\title{
Prevalence and Associated Risk Factor for Pulmonary Tuberculosis Patients in Southwestern Ethiopia: A Three-Year Retrospective Study
}

\author{
Yohannes Haile Menuta \\ Department of Statistics, College of Natural and Computational Science, Wolkite University, Wolkite, Ethiopia \\ Email address: \\ kerod89@gmail.com \\ To cite this article: \\ Yohannes Haile Menuta. Prevalence and Associated Risk Factor for Pulmonary Tuberculosis Patients in Southwestern \\ Ethiopia: A Three-Year Retrospective Study. American Journal of Health Research. Vol. 7, No. 5, 2019, pp. 85-88. \\ doi: 10.11648/j.ajhr.20190705.15
}

Received: May 24, 2019; Accepted: July 18, 2019; Published: October 12, 2019

\begin{abstract}
Tuberculosis (TB) is the leading cause of mortality among infectious diseases worldwide and $95 \%$ of TB cases and $98 \%$ of deaths due to tuberculosis occur in developing countries. Tuberculosis remains a major global health problem, responsible for ill health among millions of people each year, particularly in low-income and middle-income countries. The study was aimed to identify the prevalence and associated risk factor of pulmonary TB patient in Woliso Town. Descriptive statistics were used to present the data and logistic regression was applied to check the association between the dependent and independent variables. A total of $547 \mathrm{~TB}$ patients were included from hospital records. Majority of the patients were female $(59.6 \%)$ and rural residents $(67.2 \%)$. In addition, clinical record of the patients showed that more than half (66.6\%) and 181 (33.1\%) were $\mathrm{PTB}^{-}$and $\mathrm{PTB}^{+}$patients, respectively. In multivariate logistic regression result, there was significant effect on the prevalence of PTB being female $(P=0.00)$, age between 31-45 year $(p=0.03)$, age between $46-60$ year $(p=0.00)$, weight found between $41-61 \mathrm{~kg}(\mathrm{p}=0.015)$, rural residence $(\mathrm{p}=0.03)$, married patient $(\mathrm{p}=0.014)$ and relapse $(\mathrm{p}=0.000)$. The findings show that the prevalence of pulmonary tuberculosis was high. The study also indicates that sex, age, residence, marital status, weight, and, condition of relapsing had significant effect on prevalence of PTB.
\end{abstract}

Keywords: Prevalence, Risk Factor, Pulmonary Tuberculosis, Woliso Lukas Hospital, Southwestern, Ethiopia

\section{Introduction}

Tuberculosis is at least as old as mankind and mycobacterium are believed to be amongst the oldest bacteria on earth. Tuberculosis causes approximately $6 \%$ of all deaths worldwide [1]. According to conservative estimates around 2 million new cases of tuberculosis are seen each year. The total number of cases of tuberculosis in the world is placed at 15-20 million. The disease is on the rise and available statistics with WHO show that annual incidence of tuberculosis may reach 300 per 100, 000 inhabitants in parts of Asia [2].

Tuberculosis (TB) is the leading cause of mortality among infectious diseases worldwide and $95 \%$ of TB cases and $98 \%$ of deaths due to tuberculosis occur in developing countries [3]. Tuberculosis remains a major global health problem, responsible for ill health among millions of people each year, particularly in low-income and middle-income countries. Of the estimated 9.6 million people who developed tuberculosis globally in 2014, India accounted for $23 \%$ and China accounted for $10 \%$ [4]. The prevalence of TB disease is the number of TB cases that exist in the population at a given point in time. It is usually reported as the total number of prevalent cases in a country, or as the number of prevalent cases for a given unit of population.

Tuberculosis (TB) is one of the most challenging communicable diseases for developing countries particularly in Sub-Saharan Africa. A total of 8.8 million incident TB cases have been registered in 96 countries in 2010 [5]. African countries south of the Sahara including Ethiopia are heavily affected by TB. The World Health Organization (WHO) global reports on TB showed that Ethiopia is among the ten top high burden countries in terms of prevalence or incidence cases of TB $[6,7]$. 
It is clearly known that pulmonary TB and its complication are also common in our country and studies done previously showed that there is currently high prevalence of pulmonary TB related to death rate. Therefore, the study was aimed to identify prevalence and risk factor of Pulmonary TB patients in Woliso Lukas hospital. Even though the existence of the problem of pulmonary TB in country level was confirmed by different scholars, but there was no studies conducted in this study area regard to the problem. This makes the researcher to plan to conduct the research in the area.

The General Objective

The general objective of this study was to determine the prevalence and associated risk factors of pulmonary $\mathrm{TB}$ patients in Woliso Lukas Hospital.

The Specific Objectives

1) To determine the prevalence of pulmonary TB patients

2) To examine the association between prevalence of pulmonary TB with various predictor variables

3) To identify associated risk factors that affects the prevalence of pulmonary TB

\section{Material and Methods}

\subsection{Study Setting and Design}

A health facility-based study was conducted between January 11, 2018 and January 30, 2018 in Woliso Lukas Hospital. A retrospective study was conducted in Woliso Town, the capital city of Southwest Showa zone of Oromia region. Woliso Lukas hospital is located, $96 \mathrm{~km}$ Southwest of Addis Ababa. In Woliso town, ethnically the population is composed of almost every nation and nationalities of Ethiopia. Because of its economic and political importance of Woliso is becoming the center of different governmental and private investment sectors. At the moment the town of Woliso has area coverage of 2,225.25 hectare and a population of 53,000. A retrospective analysis of the profile and treatment outcome of all TB patients registered from January 01, 2016 to January 11, 2018. Information retrieved from the records includes sociodemographic profile and clinical information of the patients. Data were collected in data collection format prepared for this purpose. The data from the three-year records were retrieved by the research team members.

\subsection{Study Population}

The study population is TB patients registered to Woliso Lukas hospital in the past three years; totally, there are 547 TB patients in the hospital. The study was considered all TB patients from January 01, 2016 to January 11, 2018 they served.

\subsection{Inclusion and Exclusion Criteria}

All forms of TB cases which were registered in the TB clinic of the hospital were included in the study. Specially, the study includes all TB patients whose age were above fifteen years under the given study period. However, registries in which treatment outcomes were missing, and patients who transferred to other districts were excluded from the treatment outcome evaluation, as information on their treatment outcome was not available.

\subsection{Study Variables}

The dependent variable for this study is prevalence of TB patients, and is categorized as (pulmonary TB-Positive, pulmonary TB-Negative).

The independent variables were sex, age, weight, place of residence, marital status and a condition of relapsing of the patients.

\subsection{Study Instruments}

In this study secondary data were extracted from hospital registration/records. That is, demographic, socio-economic and clinical/medical information was collected from patent's information card.

\subsection{Data Collection}

Data collection was carried out by a team comprising of 6 students identified from the medical class of public health of Wolkite University and the data was gathered from patient's registrations slip regarding to TB patients. The request for the grant of permission to conduct research to Woliso Lukas Hospital was submitted and the permission was granted.

\subsection{Ethical Considerations}

The study was approved by Ethical Review Committee (ERC) of Wolkite University. An official letter was written from Wolkite University to Woliso Lukas Hospital. The study protocol was approved by the ethical review committees of Woliso Lukas Hospital. A work shop was held with the data collector, the clerk and health office representatives to create awareness about the purpose of the study.

\subsection{Data Analysis}

Data was analyzed using SPSS for windows, version 20. To ensure quality of the data, two individuals independently cross-checked each entry. Bivariate analysis with the chi-squared test was used to compare proportions. Probability values ( $p$-values) were set at 0.05 level of significance and Confidence Intervals (CIs) were calculated at the $95 \%$ level. To identify independent predictors for the prevalence of pulmonary $\mathrm{TB}$, variables found significant in the bivariate analysis $(p$-value $=0.05)$ were fitted in to a stepwise multivariate logistic regression model assuming variable categories were mutually exclusive and exhaustive; and there was no linear relationship between the dependent and independent variables. The model goodness-of-fit was tested using the Pearson's Chi-square, the likelihood ratio (LRT), Hosmer and Lemeshow and Wald tests. 


\section{Results}

Socio-demographic and clinical characteristics of the patients: Socio-demographic profile and other clinical information of a total of 547 registered TB patients was obtained and included for further analysis (Table 1). Majority of the patients were female $(59.6 \%)$ and rural residents $(67.2 \%)$. One hundred eighty nine (34.6\%), 229 (41.9\%), 81 $(14.8 \%)$ and $48(8.8 \%)$ of the patients were within the age group 16-30,31-45,46-60 and above 60 years, respectively. Clinical record of the patients showed that more than half $(66.6 \%)$ and $181(33.1 \%)$ were $\mathrm{PTB}^{-}$and $\mathrm{PTB}^{+}$patients, respectively. In addition, one hundred eighty eight (34.4\%), $284(51.9 \%), 43(7.9 \%)$ and $32(5.9 \%)$ of the patient were single, married, divorced and widowed respectively.

Table 1. Socio-demographic characteristics of Pulmonary Tuberculosis Patients in Woliso district, Southwestern, Ethiopia, 2018.

\begin{tabular}{lllll}
\hline Characteristics & Categories & $\begin{array}{l}\text { PTB- } \\
\text { positive (\%) }\end{array}$ & $\begin{array}{l}\text { PTB- } \\
\text { negative (\%) }\end{array}$ & Total (\%) \\
\hline \multirow{2}{*}{ Sex } & Male & $138(62.4)$ & $83(37.6)$ & $221(40.4)$ \\
& Female & $43(13.2)$ & $283(86.8)$ & $326(59.6)$ \\
Age group in & $16-30$ & $46(24.3)$ & $143(75.7)$ & $189(34.6)$ \\
year & $31-45$ & $40(17.5)$ & $189(82.5)$ & $229(41.9)$ \\
& $46-60$ & $66(81.5)$ & $15(18.5)$ & $81(14.8)$ \\
Weight group in & $>60$ & $29(60.4)$ & $19(39.6)$ & $48(8.8)$ \\
Kg & $21-40$ & $28(23.0)$ & $94(77.0)$ & $122(23.2)$ \\
& $41-60$ & $129(34.6)$ & $244(65.4)$ & $373(68.2)$ \\
& $>60$ & $24(46.2)$ & $28(53.8)$ & $52(9.5)$ \\
Marital status & Single & $79(42.0)$ & $109(58.0)$ & $188(34.4)$ \\
& Married & $88(31.0)$ & $196(69.0)$ & $284(51.9)$ \\
& Divorced & $9(20.9)$ & $34(79.1)$ & $43(7.9)$ \\
Residence & Widowed & $5(15.6)$ & $27(84.4)$ & $32(5.9)$ \\
Condition of & Urban & $93(52.8)$ & $83(47.2)$ & $176(32.2)$ \\
relapse & Rural & $88(23.7)$ & $283(76.3)$ & $371(67.8)$ \\
Total (\%) & No & $157(68.6)$ & $72(31.4)$ & $229(41.9)$ \\
\hline
\end{tabular}

According to the result from chi-square test given on the (Table 2), which shows the prevalence of PTB were significantly associated with sex, age, body weight, marital status, place of residence and condition of relapsing because the $\mathrm{p}$-value is less than 0.05 .

Table 2. Association of Prevalence of PTB Patients with independent variable, in Woliso district, Southwestern, Ethiopia, 2018.

\begin{tabular}{llll}
\hline Characteristics & $\begin{array}{l}\text { Pearson } \\
\text { chi-square }\end{array}$ & $\begin{array}{l}\text { Prevalence of PTB } \\
\boldsymbol{D} \boldsymbol{f}\end{array}$ & $\begin{array}{l}\text { Asymp.sig. } \\
\text { (2-sided) }\end{array}$ \\
\hline Sex & 144.314 & 1 & .000 \\
Age in year & 133.643 & 3 & .000 \\
Weight in kg & 10.049 & 2 & .007 \\
Marital status & 14.621 & 3 & .000 \\
Residence & 45.723 & 1 & .000 \\
$\begin{array}{l}\text { Condition of } \\
\text { relapsing }\end{array}$ & .223 .830 & 1 & .000 \\
\hline
\end{tabular}

In the multivariate analysis (Table 3 ) showed that, the prevalence of PTB being female $(\mathrm{P}=0.00)$, age found between 31-45 year $(p=0.03)$, age of $46-60$ year $(p=0.00)$, weight between 41-61 $\mathrm{kg} \quad(\mathrm{p}=0.015)$, rural residence $(p=0.03)$, married patient $(p=0.014)$ and relapse $(p=0.000)$ were significantly affect the prevalence of PTB, with the model goodness-of-fit results indicating Chi-square $(\mathrm{df}=8$, $\mathrm{n}=547, \mathrm{p}=0.795)=4.64$.

Table 3. Multivariate logistic regression analysis showing factors associated with PTB patients Woliso district, Southwestern, Ethiopia, 2018.

\begin{tabular}{llll}
\hline Characteristics & Categories & P-value & AOR(95\%CI) \\
\hline Sex & Male & & $\mathbf{1}$ \\
\hline \multirow{4}{*}{ Age in year } & Female & .000 & $.77(0.039-0.152)$ \\
& $15-30$ & .000 & 1 \\
& $31-45$ & .003 & $5.752(1.842-17.961)$ \\
& $46-60$ & .000 & $12.053(3.850-37.730)$ \\
Weight in Kg & Above60 & .099 & $.344(.97-1.22)$ \\
& $20-40$ & .017 & 1 \\
Residence & $41-61$ & .015 & $4.675(1.346-16.240)$ \\
& Above61 & .377 & $1.621(.555-4.736)$ \\
& Urban & .003 & 1 \\
Marital status & Rural & .005 & $.370(.193-.710)$ \\
& Single & .014 & $.130(.026-.657)$ \\
& Married & .105 & $.270(.055-1.313)$ \\
Relapse & Widowed & .787 & $1.333(.165-10.786)$ \\
& Divorced & .000 & 1 \\
\hline
\end{tabular}

\section{Discussion}

In this retrospective study, complete information was extracted from TB registration documents for a total of 547 registered TB patients. Most of the patients were female which is similar to previous studies done in Gondar [11] and Gambella [12]. The odd of females living with PTB was $77 \%$ times less likely than the odds of males living with PTB, this finding directly similar to the outputs found by [8, 9, and 13]. The percentage of deaths and defaulters was higher in females than in males.

The disease is seriously requires a relatively long and strongly increase the risk is often the working group the age between 15 and 64 [10]. Moreover, according to the study [14] the same age group was selected, $67.70 \%$ patients were in $4^{\text {th }}$ to 5 th decade of ages of patients who were positive pulmonary tuberculosis. The finding of this study also shows the age group a patient between 30-60 years was strongly increases the risk of the disease.

Similarly, place of residence is a significance factor contributing to being positive PTB. Patients come from rural residence were more likely to be positive PTB than urban residence. These finding compatible with previous studies by $[8,9,13]$ which were living in rural area had significance effect on prevalence of PTB.

\section{Conclusion}

The findings of this study indicate that the prevalence of PTB patients were associated with sex, age, residence, marital status, weight, and condition of relapsing. In multivariate logistic regression result indicate that the factors sex, age, residence, marital status, weight, and, condition of relapsing had significant effect on prevalence of PTB. Tuberculosis was associated with some social demographic characteristics and 
clinical variables. Working age group patients were the most affected by tuberculosis. There were also significant differences on the prevalence of pulmonary tuberculosis between males and females, males being more affected.

\section{Funding}

Wolkite University (funder) had no role in the study design, data collection and analysis, decision to publish, or preparation of the manuscript. Wolkite University had no grant numbers. The university gives financial support for researchers who submit the proposals.

\section{Acknowledgements}

The author of this study would like to thank the supervisors, data collectors and data clerks. Moreover, the author thanks go to the TB clinic staff members of Woliso Lukas Hospital who have helped us during data collection.

\section{References}

[1] Ravilglon MC, O’ Brien RJ. Tuberculosis in: Fauce AS, Braunwald, Isselacher KJ, Wilson JD, Martin JB, Kaspr DL, Longo L. Harrison's Principles of Internal Medicine. 14th edition. New York: McGraw-Hill Companies, 1998: 10041014 .

[2] Yad I, Pathan AJ, Iliyas M. Community Medicine and Public Health 4 th edition. Karachi: Time Reader, 1997: 544-45.

[3] Rajeswari R, Balasubramanian R, Muniyandi M, Geetharamani S, Thresa X, Venkatesan P. Socioeconomic impact of tuberculosis on patients and family in India. Int $\mathrm{J}$ Tuberc Lung Dis 1999; 3: 869-77.

[4] World Health Organization (WHO). Global tuberculosis report 2015: 20th edition. Geneva: World Health Organization, 2015.
[5] World Health Organization (WHO). Global Tuberculosis $\begin{array}{lll}\text { Report. } & \text { WHO } & \end{array}$ [http://www.who.int/tb/publications/global report/en/].

[6] World Health Organization (WHO). Global tuberculosis control: epidemiology, strategy, financing: WHO report 2009. WHO, Geneva; WHO/HTM/TB/2009.411.

[7] World Health Organization (WHO). Global tuberculosis control: epidemiology, strategy, financing: WHO report 2010. WHO, Geneva; WHO/HTM/TB/2009.411.

[8] Biadglegne F, Anagaw B, Debebe T, Anagaw B, Tesfaye W, Tessema A.( 2013). A retrospective study on the outcomes of tuberculosis treatment in Felege Hiwot Referral Hospital, Northwest Ethiopia. Int J Med Med Sci. 2013; 5 (2): 85-91.

[9] Nwene K. E. Evaluation of Treatment Outcome in Tuberculosis Directly Observed Treatment Short Course (DOTS) Facilities in Anambra State (2004-2008).

[10] Minster of Health (MOH). The Global Fund to Fight AIDS, TB and malarial Ethiopia proposal 2 nd edition.

[11] Tessema B, Muche A, Bekele A, Reissig D, Emmrich F, Sack U. Treatment outcome of Tuberculosis patients at Gondar University Teaching Hospital, Northwest Ethiopia. A fiveyear retrospective study. BMC Public Health.2009; 9:371. doi: 10.1186/1471-2458-9-371 PMID: 19799801.

[12] Sisay S, Mengistu B, Erku W and Woldeyohannes D. Directly Observed Treatment Short-course (DOTS) for tuberculosis control program in Gambella Regional State, Ethiopia: ten years experience BMC Research Notes. 2014; 7:44. doi: 10.1186/1756-0500-7-44 PMID: 24444379.

[13] Qayyum, M. Shafiq And Azfar Farogh. Prevalence of Pulmonary Tuberculosis Among Diabetics. Biomedica Vol. 20, 2004;

[14] Peierdun Mijiti, Li Yuehua, Xue Feng, Paul J Milligan, Corinne Merle, Wu Gang, Liu Nianqiang, Halmurat Upur. Prevalence of pulmonary tuberculosis in western China in 2010-11: a population-based, cross-sectional survey. 